$18^{\text {th }}$ Conference of the Egyptian Society of Animal Production, Hurghada, Egypt, November 7 - 10, 2018

\title{
INFLUENCE OF CORIANDER AND LACTOBACILLUS ACIDOPHILUS ON PERFORMANCE OF GROWING RABBITS
}

\section{M.A. Kobeisy, M.N. Mahmoud, M.M. Farghaly and Yasmin A. Gomaa}

Animal Production Dept., Faculty of Agriculture, Assiut University, Assiut, Egypt

This study was performed to compare the efficacy of coriander seed with that of Lactobacillus acidophilus on growth performance, cecal bacterial count and mortality rate. A total of 40 rabbits (Californian) of both sex were weaned at 35 days. They were randomly assigned to one of the following four dietary groups: no supplement (control), $1.5 \%$ coriander seeds, Lactobacillus acidophilus $10^{7} \mathrm{cfu} / \mathrm{kg}$ and both coriander seeds and lactobacillus. Coriander seeds fed as $1.5 \%$ of feed and lactobacillus was administered daily. Data were statistically analyzed using the GLM procedure of SAS (SAS, 2000). Coriander seed, Lactobacillus acidophilus or their combination improved the body weight gain, feed conversion ratio (FCR) and performance index. Coriander seed alone was the most effective treatment. No significant cecal bacterial count were observed compared with that of control group, however total bacterial count increased by about 17 , 10 and $11 \%$ in favor of coriander seed ,Lactobacillus acidophilus and both treatments, respectively. The mortality rate was significantly decreased in the treated groups. These results suggest that coriander seed supplement was more effective than Lactobacillus acidophilus or their combination in enhancing the growth performance without adverse effects. 